\title{
Retraction Note: Groundwater quality characteristics based on remote sensing images and influencing factors of English network autonomous learning
}

\section{Xu Xin ${ }^{1}$}

Published online: 3 November 2021

(c) Saudi Society for Geosciences 2021

Retraction Note to: Arabian Journal of Geosciences (2021) 14: 1029

https://doi.org/10.1007/s12517-021-07362-2

The Editor-in-Chief and the Publisher have retracted this article because the content of this article is nonsensical. The peer review process was not carried out in accordance with the Publisher's peer review policy. The authors have not responded to correspondence regarding this retraction.

The original article can be found online at https://doi.org/10.1007/ s12517-021-07362-2.

$\mathrm{Xu}$ Xin

xxxuxin2021@163.com

School of Basic Science, Shandong Institute of Petroleum and Chemical Technology, Dongying 257000, Shandong, China 